\title{
sciendo
}

\author{
Current Issues in Pharmacy and Medical Sciences \\ Formerly ANNALES UNIVERSITATIS MARIAE CURIE-SKLODOWSKA, SECTIO DDD, PHARMACIA \\ journal homepage: http://www.curipms.umlub.pl/
}

\section{Role of stable hydrogen isotope variations in water for drug dissolution managing}

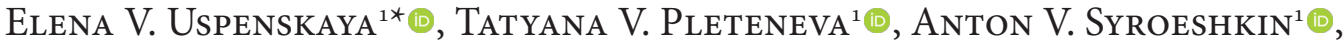 \\ Ilaha V. Kazimova ${ }^{1}$, Tatyana E. Elizarova ${ }^{2}$, Artem I. Odnovorov ${ }^{1}$
}

${ }^{1}$ RUDN University, Department of Pharmaceutical and Toxicological Chemistry, Medical Institute of Peoples' Friendship University of Russia, Moscow Russia

${ }^{2}$ OOO "Farmanaliz" Control Analytical Laboratory, Moscow, Russia

\begin{tabular}{l}
\hline ARTICLE INFO \\
\hline Received 02 October 2019 \\
Accepted 12 November 2019 \\
\hline Keywords: \\
kinetics dissolving, \\
laser diffraction spectroscopy, \\
deuterium depleted water \\
(ddw), \\
kinetic isotope effect (KIEs), \\
water clusters, \\
antibacterial, \\
neuroprotective drugs.
\end{tabular}

\section{ARTICLE INFO}

Received 02 October 2019

Accepted 12 November 2019

\section{Keywords \\ kinetics dissolving \\ aser diffraction spectroscopy, \\ $(\mathrm{ddw})$ \\ water clusters, \\ neuroprotective drugs.}

\begin{abstract}
In the present work, we provide the results of defining by utilizing Laser diffraction spectroscopy, the kinetic isotopic effect of solvent and constant of dissolution rate $\kappa, \mathrm{s}^{-1}$ of an active pharmaceutical ingredient (API) in water with a different content of a stable ${ }_{2}^{1} \mathrm{H}$ isotope on the basis of the laws of first-order kinetics. This approach is based on the analysis of the light scattering profile that occurs when the particles of the dispersion phase in the aquatic environment are covered with a collimated laser beam. For the first time, the dependence of the rate of dissolution is demonstrated not only on the properties of the pharmaceutical substance itself (water solubility $\mathrm{mg} / \mathrm{ml}$, octanol-water partition coefficient $\log \mathrm{P}$ oct/water, topological polar surface area, Abraham solvation parameters, the lattice type), but also on the properties of the solvent, depending on the content of stable hydrogen isotope. We show that the rate constant of dissolution of a sparingly hydrophobic substance moxifloxacin hydrochloride $(\mathrm{MF} \cdot \mathrm{HCl})$ in the Mili- $\mathrm{Q}$ water is: $\mathrm{k}=1.20 \pm 0.14 \cdot 10^{-2} \mathrm{~s}^{-1}$ at $293.15 \mathrm{~K}$, while in deuterium depleted water, it is $\mathrm{k}=4.24 \pm 0.4 \cdot 10^{-2} \mathrm{~s}^{-1}$. Consequently, we have established the development of the normal kinetic isotopic effect $(\mathrm{kH} / \mathrm{kD}>1)$ of the solvent. This effect can be explained both by the positions of the difference in the vibrational energy of zero levels in the initial and transition states, and from the position of water clusters giving volumetric effects of salvation, depending on the ratio $\mathrm{D} / \mathrm{H}$. The study of kinetic isotopic effects is a method that gives an indication of the mechanism of reactions and the nature of the transition state. The effect of increasing the dissolution of the API, as a function of the $\mathrm{D} / \mathrm{H}$ ratio, we have discovered, can be used in the chemical and pharmaceutical industries in the study of API properties and in the drug production through improvement in soluble and pharmacokinetic characteristics.
\end{abstract}

\section{INTRODUCTION}

Since the discovery and release of a heavy hydrogen isotope in 1932, thanks, among other things, to the works of Harold Clayton Urey [1], based on differences in physical and chemical properties (protium) and (deuterium), a period of isotopic research began with the use of labeled atoms and the introduction of "heavy" substances into the industry. Deuterated polymers, inorganic deuterides, metal deuterides and alloy deuterides have been the hot topics studied in military and energy fields [2-4]. Deuterium offers a subtle, but sometimes powerful, medicinal chemistry tool that has

\footnotetext{
* Corresponding author

e-mail: uspenskaya75@mail.ru
}

received little attention to date in the context of new drugs [5]. There was a separate direction in the medical industry, connected with deuteration API. It was shown [6] that deuteration is a tool useful for optimization of metabolic stability and toxicity of drugs. Selective replacement of hydrogen with deuterium leads to increased bond strength that in turn increases the biological half-life and thus the metabolic stability of the drug [7-8]. At the same time, there are significant changes in pharmacokinetics and reaction rates, as well as in the changes in the ways of metabolism within the Cytochrome P450 superfamily [9]. From a clinical point of view, this can lead to increased efficiency and reduced side effects of pharmacotherapy [10]. The first deuterated drug, now approved by the U.S. Food and Drug Administration, 
is Deutetrabenazine (brand name Austedo ${ }^{\circledR}$ ). This belongs to the drug class of VMAT2 inhibitors $[11,12]$. Deuterated drugs are better tolerated, have less effects on the metabolism, less side effects associated with high concentration of the API [13].

Chemical deuteration significantly increases the efficiency of fluorescence for the oxazine dyes in deuterated solutions. This effect results from a combination of both intrinsic effects, as well as the substantial contribution from altered fluorophore-solvent interactions [14].

Water with modified isotopic composition of hydrogen, for example, deuterated/heavy water, also found its application in nuclear installations for scattering of slow neutrons $[15,16]$. The use of deuterated water as a solvent for validation of the API by NMR spectroscopy is shown [17]. The selectivity of NMR spectroscopy authenticity method for nuclei was greater if $\mathrm{D}_{2} \mathrm{O}$ was used as the solvent. The work [18] has demonstrated a large solvent isotope effect (KIE $=12.0 \pm 1.5$ at $298 \mathrm{~K}$ ) of allylindium iodide solvolysis in $\mathrm{H}_{2} \mathrm{O}$ and $\mathrm{D}_{2} \mathrm{O}$. Compared at the same temperature, $\mathrm{D}_{2}$ gas is more soluble in water than $\mathrm{H}_{2}$ gas, showing a "normal" isotope effect [19].

Differences in physical properties of water ${ }_{1}^{1} \mathrm{H}_{2} \mathrm{O}$ and ${ }_{1}^{2} \mathrm{H}_{2} \mathrm{O}$ cause abnormally high natural variations of the isotopic composition: ${ }^{1} \mathrm{H}_{2}{ }^{16} \mathrm{O},{ }^{1} \mathrm{H}_{2}{ }^{17} \mathrm{O},{ }^{1} \mathrm{H}_{2}{ }^{18} \mathrm{O},{ }^{1} \mathrm{HD}^{16} \mathrm{O},{ }^{1} \mathrm{HD}^{17} \mathrm{O},{ }^{1} \mathrm{HD}^{18} \mathrm{O}$, $\mathrm{D}_{2}{ }^{16} \mathrm{O}, \mathrm{D}_{2}{ }^{17} \mathrm{O}, \mathrm{D}_{2}{ }^{18} \mathrm{O}[20-21]$. According to the SMOW-V standard, the content of stable isotopes in natural water is $\mathrm{D} / \mathrm{H}_{\mathrm{SMOW}}=(155.76 \pm 0.05) 10^{-6}[23]$. Isotopic compositions of reactants affect the rates of chemical and biochemical reactions. Usually it is assumed that heavy stable isotope enrichment leads to progressively slower reactions. Yet the effect of stable isotopes may be nonlinear, as exemplified by the "isotopic resonance" phenomenon [24].

Solubility is one the most important physicochemical properties in various stages of drug discovery and development [25]. Low solubility in water and low bioavailability are limiting factors in oral delivery of lipophilic drugs about $85 \%$ of the best-selling drugs in the U.S. and Europe are taken orally [26]. According to [27], more than $40 \%$ of all drug candidates are classified as practically insoluble in water, consequently, they do not pass the stage of preclinical studies. In the pharmaceutical industry, various approaches are used to increase the solubility of APIs: micronization, modification of the crystal structure, salt formation, preparation of solid dispersions, self-nanoemulsifying drug delivery system, mechanochemical synthesis and others [28-30]. In recent studies it was found that the physicochemical and biological properties of API aqueous solutions - the mutarotation rates, the angle of optical rotation, the lifetime of the cell biosensor are dependent on the D/H ratios [31-34].

In this study, we proposed a novel approach to enhancing the poorly soluble drugs solubilization characteristics of different chemical and pharmacological classes, based on the stable hydrogen isotope variations in water as assessed by the Laser Diffraction Spectroscopy method.

\section{Background}

In Pharmacopoeia regulation, the "Solubility" test consists in the visual estimation of solubility of the API and excipients at a fixed temperature until the achievement of thermodynamic equilibrium comes about [35]. According to USP, the standard test is to add a measured amount of solvent to a very fine powder sample and shake continuously for 10 minutes at a temperature of $(20 \pm 2)^{\circ} \mathrm{C}$. The observation is made after cooling the solution to room temperature and vigorous shaking for 1-2 minutes: the sample is considered dissolved if observation of the solution passing through a tube does not detect its particles. The approximate solubility of a compendial substance is indicated by one of the following descriptive terms given in [36]. As regulation of test for solubility comes down to visual assessment and approximate solubility of API, we developed a technique of kinetic assessment of dissolution by Laser Diffraction Spectroscopy. The method is based on registering the light scattering indicatrix in time for the electromagnetic radiation to interact with the particles of the dispersed phase. The result of a sample dispersion decrease over the time is based upon changes in the angular distribution of the scattering intensity (Low-Angle Laser Light Scattering, LALLS): $\pi \mathrm{d} / \lambda$, where $\lambda$ - the wavelength of the electromagnetic radiation, $\mathrm{d}$ - particle size [37]. Mathematically, Laser Obscuration (LO) may be presented by the following form:

$$
\mathrm{LO}=1-\mathrm{I} / \mathrm{I}_{0)} \cdot 100 \%
$$

where, $I$ is the light intensity measured by the detector while the particle is inside the measurement cell, $I_{o}$ is the light intensity measured by the detector without the particle in the measurement cell (Figure 1).

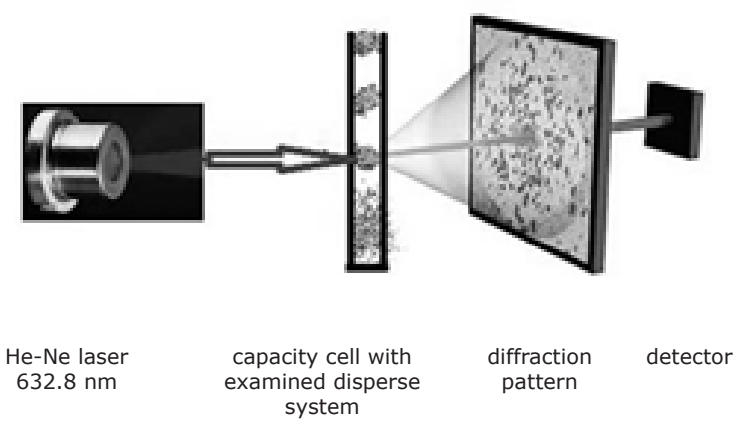

Figure 1. Optical set-up of kinetic dissolution

The LALLS method was first USP introduced in 2002 and intended for API, pharmaceutical excipients and finished drug product quality control in terms of «Particle size analysis by laser diffraction». The method is based on the ISO standards 13320:2009 [38]. The use of the method as regulated for granulometry as an instrument for studying the dissolution of the API gave us the opportunity to carry out kinetic analysis with the calculation of the rate of dissolution constant $\mathrm{k}\left(\mathrm{c}^{-1}\right)$.

\section{Effects of Isotopic Substitution on Physical and Chemical Properties of $\mathrm{H}_{2} \mathrm{O}$}

Water with modified isotopic composition of hydrogen has distinctive physical and chemical properties - the substitution of hydrogen atoms in $\mathrm{H}_{2} \mathrm{O}$ with deuterium causes significant changes in the properties of the solution [39]. However, a clear description of the effects of isotopic 
substitution at low contents of deuterium (deuterium depleted water/ddw, light water) is still lacking and of considerable scientific interest. In this work, we show that water with a low content of heavy hydrogen also has distinctive physical and chemical properties. A comparison of various properties of $\mathrm{D}_{2} \mathrm{O}, \mathrm{H}_{2} \mathrm{O}$ and ddw are given in Table 1 .

Table 1. Physical and chemical properties of $\mathrm{H}_{2} \mathrm{O}$ (water with natural content of stable hydrogen isotope), $\mathrm{D}_{2} \mathrm{O}$ and deuterium depleted water $[40,41]$

\begin{tabular}{|c|c|c|c|}
\hline \multirow[b]{2}{*}{ Properties } & \multicolumn{3}{|c|}{ Values } \\
\hline & $\begin{array}{c}\text { deuterium } \\
\text { depleted } \\
\text { water }\end{array}$ & \begin{tabular}{|c|} 
Water \\
with natural \\
content \\
of stable \\
hydrogen \\
isotope
\end{tabular} & $\begin{array}{l}\mathrm{D}_{2} \mathrm{O} \\
99.9 \%\end{array}$ \\
\hline Melting point, $\mathrm{T},{ }^{\circ} \mathrm{C}(101.325 \mathrm{kPa})$ & -1.5 & 0 & 3.82 \\
\hline $\begin{array}{l}\text { Surface-tension values } \sigma^{*}, \mathrm{mN} \cdot \mathrm{m}^{-1} \\
{ }^{*} \sigma=V_{g} / 2 n R(\rho / n), \\
\text { where } V \text { is the volume of liquid } \\
\text { corresponding to } n \text {-drops released from } \\
\text { the stalagmometer with the radius of the } \\
\text { tube } R ; \rho \text { is the fluid density } \\
{ }^{* *} \text { Properties data retrieved at } 20 \pm 0,05^{\circ} \mathrm{C}\end{array}$ & 75.172 & 72.860 & 67.800 \\
\hline Kinematic viscosity, $\mathrm{mm}^{2} / \mathrm{s}$ & 0.987 & 1.012 & 1.274 \\
\hline $\begin{array}{l}\text { Maximum density* (saturated liquid), } \\
\mathrm{g} \cdot \mathrm{Cm}^{-3} \\
{ }^{*} \text { Properties data retrieved at } 25 \pm 0,05^{\circ} \mathrm{C}\end{array}$ & 0.9969 & 0.9982 & 1.1042 \\
\hline $\begin{array}{l}D_{1}-\text { self-diffusion coefficient } *, 10^{9}, \mathrm{~m}^{2} \mathrm{~s}^{-1} ; \\
* \text { collective movements }\end{array}$ & 0.63 & 0.46 & 0.52 \\
\hline $\begin{array}{l}\text { Spin-spin relaxation time }{ }^{*} T_{2^{\prime}} \mathrm{S} \\
* \text { time constant characterizing the signal } \\
\text { decay }\end{array}$ & 0.35 & 2.000 & - \\
\hline $\begin{array}{l}\text { Volume concentration of water clusters*, } \\
\text { vc }(\%) \\
\text { * data refer to Light Scattering method }\end{array}$ & 0.20 & 1.00 & 0.18 \\
\hline $\begin{array}{l}\text { laser obscuration/light scattering* } \\
(\lambda=632.8 \mathrm{~nm}) \\
\text { * data refer to the Light Scattering method }\end{array}$ & 0.003 & 0.02 & 0.005 \\
\hline
\end{tabular}

Experimental data show the importance of the content of a heavy hydrogen isotope for measuring not only physical constants in water samples with isotope variations, but also the chemical properties of the resulting solutions $[42,43]$.

\section{Experimental}

\subsection{Water specimens}

The dissolution kinetics of APIs were investigated in two water solvents: deionized high-ohmic water $\left(>18 \mathrm{M} \Omega \cdot \mathrm{cm}^{-1}\right)$ received by means of pyrogenous distilled water purification employing the Milli-Q system (Millipore U.K.) with natural content of stable hydrogen isotope. Water, deuterium depleted $(\leq 1, \mathrm{ppm}$ Deuterium oxide) was obtained by means of liquid hydrogen low temperature vacuum rectification. Chemical Purity $-99.5 \%$ of $\mathrm{H}_{2} \mathrm{O}$ (Merck, Darmstadt, Germany). The deuterium concentration was determined by using the mass-spectrometry method and the Multipass laser absorption spectrometry method (LWIA24d instrument - produced by Los Gatos Research).

\subsection{Active Pharmaceutical Ingredients}

We utilized the ingredients of two pharmaceutical and chemical groups: topiramate - a sulphate fructopyranose derivative, neuroprotective agent and anticonvulsant that is a powder intended for the manufacture of non-sterile dosage forms (Xian Bodigard Pharmaceutical Co., Ltd., China); moxifloxacine hydrochloride - an antibacterial agent (Second Pharma Co., Ltd., Shaoxing Shi, Zhejiang Sheng, China) (Figure 2) [44-46].<smiles>CC1(C)CO[C@@H]2[C@@H](CO[C@@H]3OC(C)(C)O[C@@H]32)O1</smiles>

Topiramate

beta-D-Fructopyranose 2,3:4,5-bis-O-(1-methylethylidene)-, sulfamate

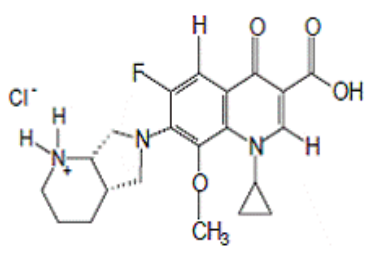

Moxifloxacine hydrochloride

3-Quinolinecarboxylic acid1-cyclopropyl-6-fluoro-1,4dihydro-8-methoxy-7-((4aS,7aS)octahydro-6H-pyrrolo(3,4-b) pyridin-6-yl)-4-oxo-, monohydrochloride
Figure 2. Chemical structures and systematic names of active pharmaceutical ingredients

\subsection{Particle sizes}

As the scattering indicatrix changes due to the relationship with $\pi \mathrm{d} / \lambda$, the rate of dissolution is proportional to the surface of the solid and inversely proportional to the diameter of the particles. We, therefore, have carried out an API particle size analysis utilizing the laser diffraction technique, according to the pharmacopoeia requirements (Figure 3).
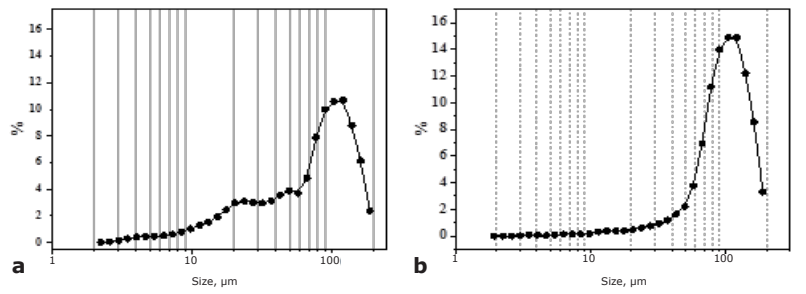

Figure 3. Laser granulometry distribution of the particle size (diameter of an equivalent sphere) in suspensions of topiramate (a) and moxifloxacine hydrochloride (b)

The substance topiramate is polydisperse and bimodal with a diameter of 20 and $120 \mu \mathrm{m}$. The particle diameter of moxifloxacin corresponds to a modal value with a diameter of $120 \mu \mathrm{m}$.

\section{RESULTS AND DISCUSSION}

\section{Kinetics of Drug Dissolution}

The kinetic involved in the dissolving of drugs were investigated by utilizing a Particle Sizer (Malvern Instruments, Malvern, UK) based on light scattering indicatrix registration in time. A 30 second background measurement was made prior to adding the examined disperse system to account for electrical background and scattering from the optics and 'clean' dispersant. Water with different contents of the heavy isotope of was used as a background. A capacity cell manufactured of quartz glass was used; the necessary quantity for the measurement of the sample material was $3 \mathrm{ml}$. The capacity cell equipped with the actuator helped to keep the particles in suspension in the process of their measurement and prevented their agglomeration; the speed of the actuator was regulated manually. 
Laser diffraction spectroscopy is based on the analysis of the intensity of angular dispersion of the monochromatic electromagnetic plane wave on particles of suspended material. Three repeated measurements were made on each aliquot, using a 30 second measurement time that is equivalent to 30,000 individual light scattering measurements [47]. The measurement of Laser Obscuration Time (LOT) was started while adding water to the cell and continued with $10 \mathrm{~s}$ intervals until the complete solubility of the substance which was recorded up to the end of change in the time of the examined laser obscuration parameter.

\section{Dissolution rate in Mili-Q water with natural stable hydrogen isotope content}

The exponential dependence of LOT values in the course of various pharmaceutical and chemical groups of powder substances dissolution is shown in Figure 4.
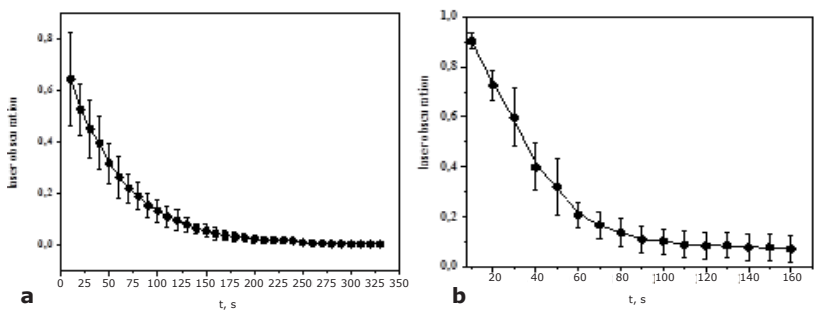

Figure 4. The dependence of the laser obscuration time values while dissolving the drug substance of topiramat (a) and moxifloxacine hydrochloride (b) in the Mili-Q with natural stable hydrogen isotope content $(n=5, p=0.95)$

The kinetics of API's dissolution in Mili-Q water are a two-step process: a sharp decrease in the recorded LOT parameter of the test substance powder from the onset of dissolution (first stage) is replaced by a gradual decrease in the laser obscuration value to reach the plateau (second stage). We had fixed it as a complete dissolution of the substance. The first stage is the speed - determining.

The rate of dissolution of substances in water is associated with both the thickness of the diffusion layer and the concentration gradient. The heterogeneous dissolution process of API is limited by diffusion, adsorption, and desorption according to Fick's law and the dissolution of the Nernst-Shchukarev equation:

$$
\begin{gathered}
\mathrm{dC} / \mathrm{dt}=\mathrm{kS}\left(\mathrm{C}_{\text {saturated }}-\mathrm{C}_{\mathrm{t}}\right) \\
\mathrm{k}=\mathrm{DS} / \delta \mathrm{V}
\end{gathered}
$$

The process of the API crystals dissolution in water becomes quite obvious: the dissolution rate is higher at the beginning of the process, when the difference in magnitude $\left(\mathrm{C}_{\text {saturated }}-\mathrm{C}_{\mathrm{t}}\right)$ is maximized within the diffusion layer, and then gradually reduced to a plateau.

If we assume that the change in the concentration of one of the reagents - the solvent in the process of dissolution can be neglected, then the general order of the kinetic equation is equal to unity and the reaction proceeding in such conditions is of the pseudo-first order [48].

$$
\mathrm{V}=-\mathrm{dC} / \mathrm{dt}=\mathrm{kC}
$$

The final expressions are given by:

$$
\begin{gathered}
\mathrm{k}=1 / \mathrm{t} \ln \mathrm{C}_{0} / \mathrm{C} \\
\mathrm{C}=\mathrm{C}_{0} \mathrm{e}^{-\mathrm{kt}}
\end{gathered}
$$

And to be satisfied are: $\mathrm{C}=\mathrm{C}_{0}$ at $\mathrm{t}=0$.

Equation 6 proves an exponential decrease in the time of the concentration of one of the reagents. According to a technique based on the method of laser light diffraction, this means a decrease in laser dimming, which depends on the dispersion of the medium.

We calculated the values of the constant dissolution rate of log-linearizing of equation 6 :

$$
\begin{gathered}
\mathrm{y}=\mathrm{a}+\mathrm{bx} \\
\mathrm{k}=-\operatorname{tg} \alpha \\
\operatorname{tg} \alpha=-\mathrm{d} \text { laser obscuration/dt }
\end{gathered}
$$

The reaction rate constant is determined by the coefficient $b$ of the equation 7 of a straight line, as the tangent of the angle of inclination to the abscissa axis in Figure 5.
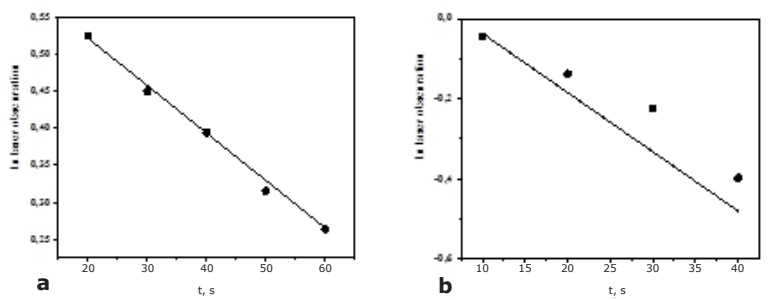

Figure 5. The dependence of the natural logarithm of laser obscuration values of topiramate (a) and moxifloxacine hydrochloride (b) dissolving in the water with natural stable hydrogen isotope content, plotted versus $t, \mathrm{~s}(\mathrm{n}=5, \mathrm{p}=0.95)$

\section{Dissolution rate in Water, deuterium depleted}

The analysis of exponential curves dissolution kinetics of the powder of poorly soluble drugs in deuterium depleted water, when compared with that in normal water, allowed identifying differences such as that dissolution is twice as fast as in the Mili-Q water with natural content of in linear (a, b) and semi-logarithmic (c, d) coordinates (Figure 6).

The results in Figs. 4 and 6 indicate that the dissolution of poorly soluble drugs increases with decreases in the stable hydrogen isotope content in water, both for the neuroprotective and antibacterial drug substances. The higher dissolution rate of poorly soluble drugs in the ddw indicates that the $\mathrm{D} / \mathrm{H}$ ratio plays a significant role in the dissolution.

\section{Kinetic isotope effect (KIE) for solvent. Elements of statistical analysis}

The study of the API's dissolution kinetics showed the development of a normal kinetic isotope effect when the condition is: $\mathrm{k}_{\mathrm{H}} / \mathrm{k}_{\mathrm{D}}>1$. Validation of the analytical method for determining the dissolution rate of the API by laser diffraction spectroscopy was carried out via repeatability and intermediate precision parameters. For the 
statistical analysis of graphic data we applied the software package of OriginLab Corporation (USA).
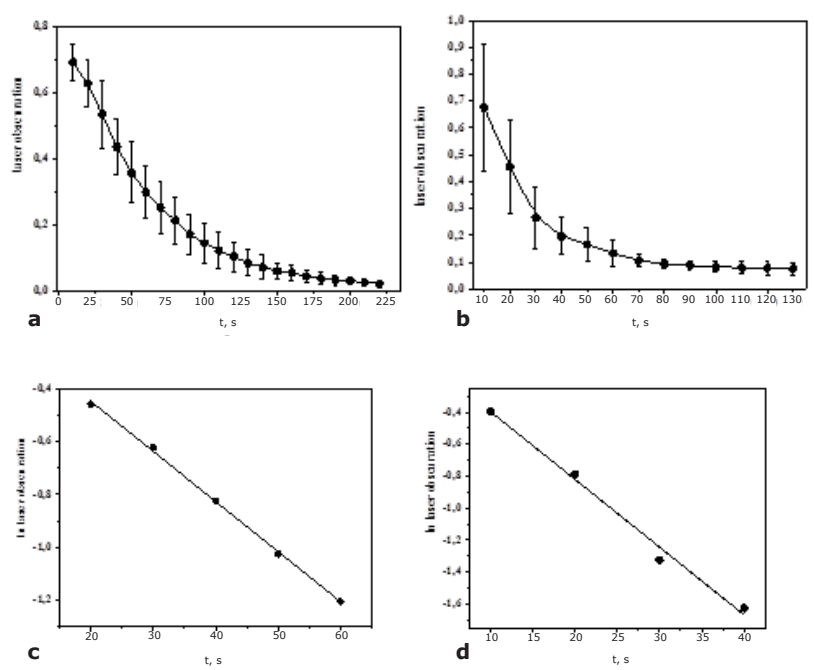

Figure 6. The dependence of laser obscuration values while dissolving the drug substance of topiramat $(\mathrm{a}, \mathrm{c})$ and moxifloxacine hydrochloride $(b, d)$ in water, deuterium depleted in linear and semi-logarithmic coordinates, plotted versus $\mathrm{t}, \mathrm{s}(\mathrm{n}=5, \mathrm{p}=0.95)$

The repeatability of the technique was evaluated with identical conditions on the same subjects within a short period of time (Table 2) [49].

Table 2. Evaluation of the rate constant of poorly soluble drugs dissolution in water with stable hydrogen isotope variations with the observed kinetic isotope effect (KIE) $(n=5, p=0.95)$

\begin{tabular}{|c|c|c|c|c|c|}
\hline Sample & \multicolumn{2}{|c|}{$(\bar{k} \pm \mathrm{SD}) \cdot 10^{2}, \mathrm{~s}^{-1}$} & \multicolumn{2}{c|}{\begin{tabular}{c}
\multicolumn{2}{c|}{$\mathrm{tp}, \mathrm{f}=2,78, \mathrm{O} 0^{2}$} \\
$\mathrm{n}=5, \mathrm{f}=4$
\end{tabular}} & $\mathrm{kH} / \mathrm{kD}$ \\
\hline \multirow{3}{*}{ Topiramat } & $\begin{array}{c}\text { water } \\
\text { with natural } \\
\text { stable } \\
\text { hydrogen } \\
\text { isotope } \\
\text { content }\end{array}$ & $\begin{array}{c}\text { water, } \\
\text { deuterium } \\
\text { depleted }\end{array}$ & $\begin{array}{c}\text { water } \\
\text { with natural } \\
\text { stable } \\
\text { hydrogen } \\
\text { isotope } \\
\text { content }\end{array}$ & $\begin{array}{c}\text { water, } \\
\text { deuterium } \\
\text { depleted }\end{array}$ & \\
\cline { 2 - 6 } & $1.70 \pm 0.11$ & $1.90 \pm 0.04$ & 0.14 & 0.05 & 1.1 \\
\hline $\begin{array}{l}\text { Moxifloxacine } \\
\text { Hydrochloride } \\
(\mathrm{MF} \cdot \mathrm{HCl})\end{array}$ & $1.20 \pm 0.14$ & $4.24 \pm 0.2$ & 0.17 & 0.25 & 3.5 \\
\hline
\end{tabular}

Reproducibility (intermediate precision) as an expression of the proximity of the results between the series of measurements has been evaluated when testing in the laboratory on identical samples of the same series of API on different days $(\mathrm{n}=25, \mathrm{P}=0,95)$. The calculated values of relative standard deviation/coefficient of variation $\mathrm{RSD}, \%(\mathrm{CV}=(\mathrm{S} / \mathrm{K}) \times 100 \%)$ reveal the suitability of the developed analytical method with the use of laser diffraction spectroscopy method: $\mathrm{RSD}_{\text {topiramat/ddw }}=2.1 \% ; \mathrm{RSD}_{\text {topiramat/mili-q }}=5.8 \% ; \mathrm{RSD}_{\mathrm{MF} \cdot \mathrm{HCl} / \mathrm{ddw}}=$ $=4.7 \% ; \mathrm{RSD}_{\mathrm{MF} \cdot \mathrm{HCl} / \mathrm{mili}-\mathrm{q}}=7 \%$.

The observed KIE by the solvent for substances of different classes (see Table 2) can be explained from the position of the difference in zero energies of the bonds of isotope molecules. At the same time, the curves of the potential energy of the $\mathrm{C}-\mathrm{H}$ connection are identical with the C-D communication curves, that is, the classical energy of activation for the reactions of such molecules can be considered the same [50]. The difference in reaction speeds is due to the difference in the vibrational energy of zero levels in the initial and transition states [51]. Since zero energy is associated with the frequency of oscillation of the coupling by the expression:

$$
\mathrm{E}^{0}=1 / 2 \sum \mathrm{h} v_{\mathrm{i}}
$$

And the frequency of oscillation is represented by the expression:

$$
v i=1 / 2 \pi \sqrt{f / m^{*}}
$$

where: $m(D)=1: 2$, then the zero energy for the connection with deuterium in is less than for the connection with the protium, because the true activation energy is determined by the ratio:

$$
\mathrm{E}^{\mathrm{a}}=\mathrm{E}+\mathrm{E}_{\text {activated complex }}-\mathrm{E}^{0}
$$

Therefore, the activation energy of the link break with the proton will be less than with the deuterium.

As follows from the work on the theoretical and experimental studies of KIE [52,53], the change in the reaction rate in isotopic substitution is possible when the communication is broken at the limiting stage of the reaction. The concept of API dissolution on the example of $\mathrm{MX} \cdot \mathrm{HCl}$ in water with isotopic variations is presented in Figure 7.

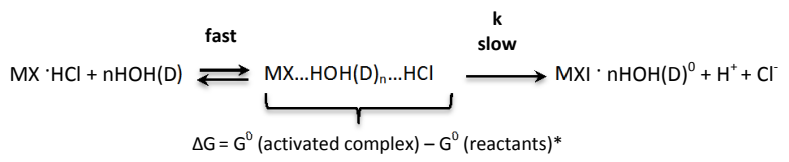

*The Transition-state Theory (TST) developed in 1935 by H. Eyring and Polanyi allows characterizing the kinetic dissolution process in terms of the enthalpy and entropy of activation

Figure 7. Solubility scheme of a drug in water with stable hydrogen isotope variations so as to form an activated complex [54]

According to the concept proposed in $[55,56]$, the ratio of velocity constants is influenced by the process of interaction with the solvent containing isotopic molecules. This interaction leads to varying degrees of polarization and hydration of reactive bonds, which is reflected in the size of the kinetic isotope effect. In addition, for hydrogen atoms, there is the possibility of a non-classical passage of the energy barrier ("tunnel"-effect) [57].

In investigating the solvation effects at 298.15 , the authors of [58] have compiled a wide variety of experimental data in order to explore the differences in solvation effects for various electrolyte and nonelectrolyte molecules between $\mathrm{H}_{2} \mathrm{O}$ and $\mathrm{D}_{2} \mathrm{O}$. Assessment of these differences consists of comparing the transfer properties, defined as:

$$
\Delta \mathrm{Y}^{0}=\overline{\mathrm{Y}}_{\mathrm{D}_{2} \mathrm{O}}-\overline{\overline{\mathrm{Y}}}_{\mathrm{H}_{2} \mathrm{O}}
$$

where $\mathrm{Y}$ is the partial molar property of the solution. These differences represent the change in solvation energy upon transfer from $\mathrm{H}_{2} \mathrm{O}$ to $\mathrm{D}_{2} \mathrm{O}$. The general idea behind the standard Gibbs energy of transfer is that it represents the difference in work done against the cohesive forces of the solvents to create a cavity where the molecule will be placed. This appears to make sense, as water with $\mathrm{D}_{2} \mathrm{O}$ 
contents is considered a more "structured" solvent at room temperature [59].

We assume that in ddw water, the hydration process (Fig. 7 stages 2) by molecular $\mathrm{HOH}$ is considerably facilitated in contrast to that by molecular deuterium stabilized water clusters in Mili-Q water containing a mixture water isotopologues: ${ }^{1} \mathrm{H}_{2} \mathrm{O} ;{ }^{1} \mathrm{HDO} ; \mathrm{D}_{2} \mathrm{O}$ and others [60]. Usually, the replacement of the protium for deuterium leads to a decrease in the reaction rate by 3-8 times [61]. In our case, the removal of deuterium from the dissolution medium led to an increase in the dissolution rate of $\mathrm{MX} \cdot \mathrm{HCl}$ by 3.5 times.

\section{Drug Dissolution Managing}

The difference in deuterium depleted water dissolution between the topiramate and the $\mathrm{MF} \cdot \mathrm{HCl}$ (showed in Table 2) also increases with their property's differences, such as, solubility, octanol-water partition coefficient log and the lattice type. It has previously been shown that the $\mathrm{D} / \mathrm{H}$ ratio is more significant for lipophilicity and sparingly/slightly soluble drugs substances [62].

Probably, the physicochemical properties of the soluble substance, including solubility, $\mathrm{pH}, \mathrm{pKa}$ and lipophilicity, which determine the main mechanisms of intake and distribution of in vivo, play an important role in the acceleration of dissolution (Table 3) [63]. It is known that the absorption process through the intestinal epithelial membrane depends on the lipophilicity of the drug and the nature of distribution and penetration through biological barriers depends on its solubility.

Table 3. Some physicochemical properties of drug substances of different pharmacological and chemical classes [64].

\begin{tabular}{|l|c|c|}
\hline \multicolumn{1}{|c|}{ Active Pharmaceutical Substance } & pKa & $\mathrm{pH}$ \\
\hline Gentamicin & 12.55 & $3.5-5.5$ \\
\hline Taurin & 1.5 & $1.4-5.6$ \\
\hline Topiramat & 11.09 & 6.3 \\
\hline Caffeine & 14 & 6.9 \\
\hline Moxifloxacin & 5.7 & $3.9-4.6$ \\
\hline Furosemid & 4.25 & 8.0 \\
\hline Dexamethason & 12.4 & $7.5-10.5$ \\
\hline Diasepam & 3 & $6.2-6.9$ \\
\hline Verapamil & 9.68 & $4.1-6.0$ \\
\hline
\end{tabular}

To explain the observed kinetic isotope effect during drug dissolution, we ranked the log $\mathrm{P}$ values for substances of different pharmacological and chemical classes in order of their water solubility increase based on reference data (Figure 8) [65].

Based on this two-dimensional diagram, we can predict the biggest kinetic isotopic effect for the substances occupying the upper left area of the diagram - characterized by hydrophobic properties and by being poorly soluble in water. As a result, the conducted studies make it possible to evaluate the important role of stable hydrogen isotope variations in water for correcting/managing the dissolution characteristics of drug substances.

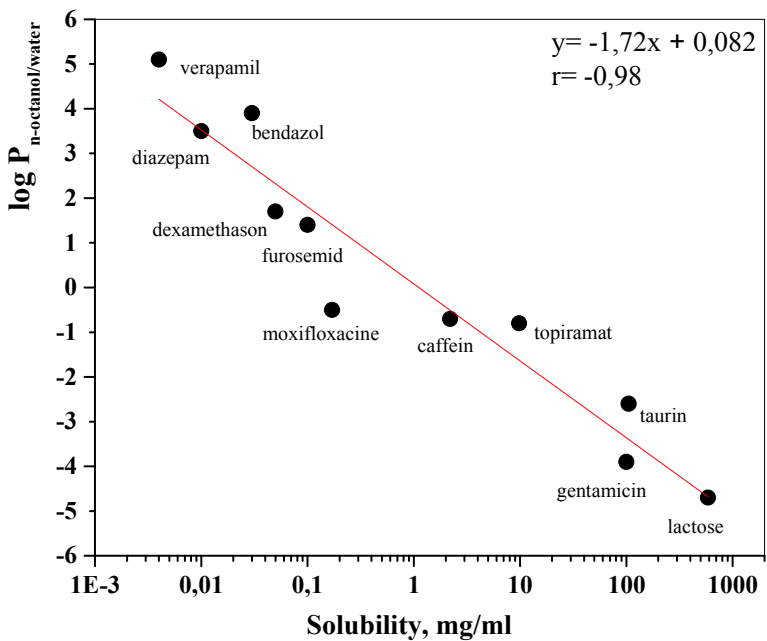

Figure 8. One-to-one correspondences: $\log \mathrm{P}$ oct/wat - solubility $(\mathrm{mg} / \mathrm{ml})$ for substances of different pharmacological and chemical classes

According to the results obtained, an increase of the API's dissolution occurs when the water solvent is deuterium depleted and this leads to the development of the normal kinetic isotope effect $\left(\mathrm{k}_{\mathrm{H}} / \mathrm{k}_{\mathrm{D}}>1\right)$ of poorly soluble drug dissolution. These results indicate a decrease in the transit time of the activated complex that is directly linked with the hydration of the API by $\mathrm{HOH}, \mathrm{HOD}$ or $\mathrm{D}_{2} \mathrm{O}$ molecules. The contribution of molecular water clusters to the kinetics of the formation and disintegration of the API hydrates by protium and deuterium molecules is shown. Consequently, the solvent can be considered as a "means of management" of the properties and processes of dissolution.

\section{CONCLUSIONS}

Considering that deuterium depleted water is a safe and accessible (as opposed to heavy water) water solvent, the results of the research will have practical application in the management of the rate of dissolution of substances in water, for example, in chemical and pharmaceutical industries in the study of API properties and in the drugs manufacture with improved solubility and pharmacokinetic characteristics.

Taking into account the previously obtained results on the rate of moxifloxacin degradation in organic solvents [66-68], we propose the unique analytical approach that is offered, consisting of an increase in speed of dissolution of slightly soluble and hydrophobic substances on the basis of variation in the isotope composition of water.

Furthermore, a technique for the kinetic evaluation of the API dissolution by Laser diffraction spectroscopy analyzer has been developed. The technique can be applied to improve and supplement the existing Pharmacopoeial solubility test.

\section{ACKNOWLEDGEMENT}

The publication has been prepared with the support of the "RUDN University Program 5-100". 


\section{ORCID iDs}

Elena V. Uspenskaya (Dhttps://orcid.org/0000-0003-2147-8348 Tatyana V. Pleteneva (Dhttps://orcid.org/0000-0001-7297-980X Anton V. Syroeshkin (Dhttps://orcid.org/0000-0003-3279-7520 Artem I. Odnovorov (1) https://orcid.org/0000-0001-9355-2522

\section{REFERENCES}

1. Urey HC, Brickwedde FG, Murphy GM. A hydrogen isotope of mass 2 and its concentration. Phys Rev. 1931;40(1):1-15.

2. Brand WA, Coplen TB. Stable isotope deltas: tiny, yet robust signatures in nature. Isot Environ Health S. 2012;48(3):393-409.

3. Mark $\mathrm{H}$. Thiemens introduction to chemistry and applications in nature of mass independent isotope effects special feature. Proc Natl Acad Sci USA. 2013;110(44):17631-7.

4. Newell RR. What's new in isotopes. Calif Med. 1950;73(1):115.

5. Jiping L, Xiaobo L. Deuteride. Deuteride materials. Amazon Digital Services LLC; 2019.

6. Sukhninder K, Monika G. Deuteration as a tool for optimization of metabolic stability and toxicity of drugs. Glob J Pharmaceu Sci. 2017;1(14):001-0011.

7. Ding Z, Hou Y, Wang S., Sun T, Ma M, Guan H, Li W. Synthesis of deuterium-enriched and fluorine-substituted plinabulin derivatives and evaluation of their antitumor activities. Mol Divers. 2017;21(3):577-83.

8. Ricardo P, Grossberg G. AVP-786 for the treatment of agitation in dementia of the Alzheimer's type. Expert Opin Investig Drugs. 2017; 26(1):121-32.

9. Merbel V, Bronsema KJ, Gorman SH, BakhtiaR. Monitoring of the deuterated and nondeuterated forms of levodopa and five metabolites in plasma and urine by LC-MS/MS. Bioanal. 2019;11(4):279-93.

10. Russak EM, Bednarczyk EM. Impact of Deuterium Substitution on the Pharmacokinetics of Pharmaceuticals. Ann Pharmacother. 2019;53(2):211-6.

11. Dean L. Deutetrabenazine Therapy and CYP2D6 Genotype. Med Genet Summ. 2012;9(1):155-65.

12. Limandri BJ. Tardive dyskinesia: New treatments available. J Psychosoc Nurs Ment Health Serv. 2019;57(5):11-4.

13. Timmins GS. Deuterated drugs; updates and obviousness analysis. Expert Opin Ther Pat. 2017;27(12):1353-61.

14. Kusinski M, Nagesh J, Gladkikh M, Izmaylov A, Jockusch RA. Deuterium isotope effect in fluorescence of gaseous oxazine dyes. Phys Chem Chem Phys. 2019;21(10):5759-70.

15. Butler D. The scattering of slow neutrons by heavy water: I. Intramolecular scattering. Proc Phys Soc. 2002;81(2):276-93.

16. Atchison F, Brandt B, Bryś T, Daum M, Fierlinger P, Hautle P, et al. Measured total cross sections of slow neutrons scattered by gaseous and liquid 2H(2). Phys Rev Lett. 2005;94(21):212-502.

17. Kuz'mina NE, Moiseev SV, Krylov VI, Deryabin AS, Yashkir VA, Merkulov VA. Validation of an NMR-spectroscopic method for authenticity confirmation of buserelin acetate pharmaceutical substance. Pharm Chem J. 2018;52:159-65.

18. Koszinowski K, Stephenson DS. Large solvent isotope effect associated with the hydrolysis of allylindium iodide. J Org Chem. 2018;83(23):14314-22.

19. Muccitelli W-Y. Wen Solubilities of hydrogen and deuterium gases in water and their isotope fractionation factor. J Sol Chem. 1978;7:257-67.

20. Shuangxi F, Qiding Z, Hongbo G, Daobing W, Guohui L, Zhanbin $\mathrm{H}$. Elemental profile and oxygen isotope ratio $(\delta 18 \mathrm{O})$ for verifying the geographical origin of Chinese wines. JFDA. 2018;26(3):1033-44.

21. Xiao W, Wen X, Wang W, Xiao Q, Xu J, Cao C, et al. Spatial distribution and temporal variability of stable water isotopes in a large and shallow lake. Isot Environ Health S. 2016;52(4-5):443-54.

22. Gabriel JB, James, RE, Lesley AC, Erik TE. Stable isotope ratios of tap water in the contiguous United States. Water Resour Res. 2007;43(3):45-65.

23. Schoenemann SW, Schauer AJ, Steig EJ. Measurement of SLAP and GISP $\delta 17 \mathrm{O}$ and proposed VSMOW-SLAP normalization for $\delta 17 \mathrm{O}$ and 17O(excess). Rapid Commun Mass Spectrom. 2013;27(5):582-90.
24. Xie X, Zubarev RA. On the effect of planetary stable isotope compositions on growth and survival of terrestrial organisms. PLoS One. 2017;12(1):1-9.

25. Shahram E, Abolghasem J, Hadi V, Ali S. Are crystallinity parameters critical for drug solubility prediction? J Sol Chem. 2015; 44(12):2297-315.

26. Eleftheriadis GK. Mantelou P, Karavasili C, Chatzopoulou P, Katsantonis DM, Irakli M, et al. Development and characterization of a self-nanoemulsifying drug delivery system comprised of rice bran oil for poorly soluble drugs. AAPS Pharm Sci Tech. 2019; 20(2):78-89.

27. Savjani KT, Gajjar AK, Savjani JK. Drug solubility: importance and enhancement techniques. ISRN Pharmaceutics. 2012;20(12):177-95.

28. Wang J, Liao Y, Xia J, Wang Z, Mo X, Feng J, et al. Mechanical micronization of lipoaspirates for the treatment of hypertrophic scars. Stem Cell Res Ther. 2019;10(1):2-10.

29. Syroeshkin AV, Uspenskaya EV, Pleteneva TV, Morozova MA, Maksimova TV, Koldina AM, et al. Mechanochemical activation of pharmaceutical substances as a factor for modification of their physical, chemical and biological properties. Int J App Pharm. 2019; 11(3):118-23.

30. Timur SS, Yöyen-Ermiş D, Esendağlı G, Yonat S, Horzum U, Esendağlı G, Gürsoy RN. Efficacy of a novel LyP-1-containing self-microemulsifying drug delivery system (SMEDDS) for active targeting to breast cancer. Eur J Pharm Biopharm. 2019; 136(1):138-46.

31. Livingstone G. Franks F, Aspinal LJ. The mutarotation rates of glucose. J Solution Chem. 1977;6(1):203-10.

32. Ulyantsev AS, Uspenskaya EV, Pleteneva TV, Popov PI, SamsoniTodorov O, Goncharuk VV, Syroeshkin AV. Rapid determination of the identity of aqueous drug solutions. Pharmaceut Chem J. 2009; 43(12):687-91.

33. Goncharuk VV, Pleteneva TV, Grebennikova TV. Syroeshkin AV, Uspenskaya EV, Antipova NV, et al. Determination of Biological Activity of Water Having a Different Isotope Ratio of Protium and Deuterium. J Water Chem Tech. 2018;40(1):27-34.

34. Syroeshkin AV, Pleteneva TV, Uspenskaya EV, Levitskaya OV, Tribot-Laspiere MA, Zlatsky IA, et al. Polarimetric research of pharmaceutical substances in aqueous solutions with different water isotopologues ratio. IJ App Pharm. 2018;10(5):243-8.

35. The United States Pharmacopeia and National Formulary USP 35NF 31. Rockville: The United States Pharmacopeial Convention, Inc;2013.

36. Anfimova EV, Uspenskaya EV, Pleteneva TV, Syroeshkin AV. Solubility kinetics of drugs studied by lalls method in water solutions with various hydrogen isotope content. Drug development \& registration. 2017;1(1):150-5.

37. Henry NC. Diffraction before destruction. B Biol Sci. 2014;17:1-13.

38. ISO 13320:2009 Particle Size Analysis - Laser Diffraction Methods. Part 1. General Principles; 2009.

39. Yacyshyn MB. Deuterium isotope effects for inorganic oxyacids at elevated temperatures using raman spectroscopy. Guelph, Ontario, Canada; 2013.

40. Arnett EM, Mckelvey DR. Solute-solvent interactions. Marcel Dekker, New York; 1969.

41. Goncharuk VV, Syroeshkin AV, Pleteneva TV, Uspenskaya EV, Levitskaya OV, Tverdislov VA. On the possibility of chiral structuredensity submillimeter inhomogeneities existing in water. J Water Chem Tech. 2017;39(1):319-24.

42. Bacsik Z, Canongiam JN, Lopes MF, Costa G, Jancsó G, Mink J, Pádua AA. Solubility isotope effects in aqueous solutions of methane. J Chem Phys. 2002;116(24):816-10824.

43. Michael R, Duff Jr, Elizabeth E. Thermodynamics and solvent linkage of macromolecule-ligand interactions. Methods. 2015;76(1):51-60.

44. Prince V, Bowling K.C. Topiramate in the treatment of cocaine use disorder. Am J Health Syst Pharm. 2018;75(1):13-22.

45. Bruno E, Nicoletti A, Quattrocchi G, Allegra R, Filippini G, Colosimo C, Zappia M. Topiramate for essential tremor. Cochrane Database Syst Rev. 2017;4(1):87-90.

46. McGee EU, Samuel E, Boronea B, Dillard N, Milby MN, Lewis SJ. Quinolone Allergy. Pharmacy. 2019;7(3):97-109. 
47. Muhlenweg H, Hirleman ED. Laser diffraction spectroscopy: Influence of particle shapeand a shape adaptation technique. Par Pa. Sys Charact. 1998;15(4):163-9.

48. Shaikh HK, Kshirsagar RV, Patil SG. Mathematical models for drug release characterization: A review. World J Phar Sci. 2015;4:324-38.

49. Bartlett JW, Frost C. Reliability, repeatability and reproducibility: analysis of measurement errors in continuous variables. Ultrasound Obstet Gynecol. 2008;31(4):466-75.

50. Piskulich ZA, Mesele OO, Thompson WH. Activation energies and beyond. J Phys Chem. 2019;123(33):7185-94.

51. Carvalho-Silva VH, Coutinho ND, Aquilant, V. Temperature dependence of rate processes beyond Arrhenius and Eyring activation and transitivity. Front Chem. 2019;7(1):1-11.

52. $\mathrm{Gu} \mathrm{H}$. Advances in kinetic isotope effect measurement techniques for enzyme mechanism study. Molecules. 2013;18(8):9278-92.

53. Francis K. On the use of nancompetitive kinetic isotope effects to investigate flavoenzyme mechanism. Metods Enzymol. 2019; 620(1):115-43

54. Uspenskaya EV, Anfimova EV, Syroeshkin AV, Pleteneva TV. Kinetics of pharmaceutical substance solubility in water with different hydrogen isotopes content. Indian J Pharm Sci. 2018;80(2):318-24.

55. Kenneth BW. The Deuterium isotope effect. Chem Rev. 1955; 55(4):713-43.

56. Saunders WH. Kinetic Isotope effects. Survey of Progress in Chemistry. 1966;3(1):109-46.

57. Hama T, Hirokazu U, Kouchi A, Watanabe N. Quantum tunneling observed without its characteristic large kinetic isotope effects. Proc Natl Acad Sci USA. 2015;112(24):7438-43.

58. Arnett EM, McKelvey DR. A large solvation enthalpy effect in highly aqueous t-butyl alcohol solutionsJ. Am Chem Soc. 1965;87(6):1393-4.

59. Némethy G, Scheraga HA. Structure of water and hydrophobic bonding in proteins. IV. The thermodynamic properties of liquid deuterium oxide. J Chem Phys. 1964;41:680-96.
60. Mysels KJ. Light scattering and the structure of pure water. JACS. 1964;86(17):3503-5.

61. Kresge AJ, Powell MF. The kinetics of isotope exchange reactions: Use of initial rates to measure isotope effects on carbon acid ionization. Int Jf Chem Kinet. 1982;14(1):19-34.

62. Syroeshkin AV, Pleteneva TV, Uspenskaya EV, Zlatskiy IA, Antipova NA, Grebennikova TV, Levitskaya OV. D/H control of chemical kinetics in water solutions under low deuterium concentrations. Chem Engin J. 2018;377:1-2.

63. Louis L, Wong H. Predicting oral drug absorption: Mini review on physiologically based pharmacokinetic models. Pharmaceutics. 2017; 9(4):41-55

64. Wishart DS, Feunang YD, Guo AC, Lo EJ, Marcu A, Grant JR, Sajed T, et al. DrugBank 5.0: a major update to the Drug Bank database for 2018. Nucleic Acids Res. 2017;46(D1):D1074-D1082.

65. National Center for Biotechnology Information. Pub Chem Database. Verapamil, CID =2520, https://pubchem.ncbi.nlm.nih.gov/ compound/Verapamil (accessed on Dec. 13, 2019)

66. Ahmad I, Bano R, Musharraf SG, Ahmed S, Qamar A, Bhatti MS, Shad Z. Photodegradation of moxifloxacin in aqueous and organic solvents: A kinetic study. AAPS Pharm Sci Tech. 2014;15(1):1588-97.

67. Matsuura K, Suto C, Akura J, Inoue Y. Comparison between intracameral moxifloxacin administration methods by assessing intraocular concentrations and drug kinetics. Graefe's Arch Clin Expl Ophthal. 2013;251(1):1955-9.

68. Avcıbașı U, Demiroğlu H, Sakarya S. Ünak P, Tekin V, Ateş B. The effect of radiolabeled antibiotics on biofilm and microorganism. J Radioanal Nucl Chem. 2018;316(1):275-87. 